\title{
Estudo de implantação de sinalização vertical de um aeroporto da Amazônia
}

\author{
Implementation study of vertical signaling of an Amazon airport \\ Estudio de implementación de señalización vertical de un aeropuerto Amazónico
}

\begin{abstract}
Resumo
O aeroporto é essencial para o transporte aeroviário, principalmente por o ser o local onde ocorre a transferência dos modais de transporte aéreo e terrestre e, vice-versa. Em se tratando do aeroporto de Santarém, há também de frisar sua posição estratégica na Amazônia, por estar situado geograficamente entre o eixo Manaus e Belém, os quais concentram as maiores operações da região. Deste modo, o presente trabalho tem o intuito de verificar a infraestrutura de sinalização luminosa vertical do Aeroporto de Santarém, comparando-a com as exigências normativas, assim como, descrever uma sequência de procedimentos metodológicos a serem referenciados na elaboração de projeto de aeroportos regionais de pequenos portes. Com os dados, foi possível propor um sistema de sinalização vertical luminosa com alta eficiência energética, garantindo a segurança operacional e atendendo aos normativos vigentes. Sendo assim, definiu-se as características dos painéis de instrução obrigatória, de informação, de localização e destino, os transformadores de alimentação, abrigos para os transformadores e suas conexões.
\end{abstract}

Palavras-chave: Aeroporto; Segurança operacional; Sinalização vertical.

\begin{abstract}
The airport is essential for air transport, mainly because it is and place where the transfer of air and land transport modes takes place and, vice versa. In the case of Santarém airport, it is also important to stress its strategic position in the Amazon, as it is geographically located between the Manaus and Belém axis, which concentrate the largest operations in the region. In this way, the present work intends to verify the vertical light signaling infrastructure of Santarem Airport, comparing it with the normative requirements, as well as to describe a sequence of methodological procedures to be referenced in the elaboration of a regional airport project. With the data, it was possible to propose a vertical light signaling system with high energy efficiency, guaranteeing operational safety and complying with current regulations. Thus, the characteristics of the mandatory instruction, information, location and destination panels, power transformers, shelters for transformers, and their connections were defined.
\end{abstract}

Keywords: Airport; Operational safety; Vertical signaling.

\section{Resumen}

El aeropuerto es fundamental para el transporte aéreo, principalmente porque es el lugar donde se realiza la transferencia de los modos de transporte aéreo y terrestre y viceversa. En el caso del aeropuerto de Santarém, también es importante resaltar su posición estratégica en la Amazonía, ya que se ubica geográficamente entre los ejes Manaus y Belém, que concentran las mayores operaciones de la región. Así, el presente trabajo tiene como objetivo verificar la infraestructura de señalización luminosa vertical del aeropuerto de Santarém, comparándola con los requisitos normativos, así como describiendo una secuencia de procedimientos metodológicos a ser referenciados en el diseño de proyectos de aeropuertos regionales. Con los datos se pudo proponer un sistema de señalización luminosa vertical con alta eficiencia energética, garantizando la seguridad operativa y cumpliendo con la normativa vigente. Por lo tanto, se definieron las características de los paneles de instrucción obligatoria, información, ubicación y destino, los transformadores de potencia, refugios para los transformadores y sus conexiones. 
Palabras clave: Aeropuerto; Seguridad operacional; Señalizacion vertical.

\section{Introdução}

O município de Santarém pertence à mesorregião do Baixo Amazonas, Oeste do estado do Pará, em uma posição estratégica, na qual exerce, desde o período colonial, importante papel e influência nessa porção do território paraense, firmandose desde então, como o principal entreposto comercial no eixo Manaus, Amazonas e Belém do Pará (Silva et al., 2019).

Neste cenário está inserido o Aeroporto de Santarém, fundado em 31 de março de 1977, período no qual o Governo Federal tinha como meta, entre outras, a integração da Amazônia aos estados das demais regiões brasileiras. Em 1980 o aeroporto foi incorporado à Empresa Brasileira de Infraestrutura Aeroportuária (Infraero), com isso a empresa pública passou a administrar, operar e explorar industrial e comercialmente a infraestrutura aeroportuária. Vale ressaltar, que sob uma perspectiva geográfica os aeroportos regionais são essenciais para muitas cidades e regiões do Brasil, sendo um diferencial entre o isolamento territorial e a política estratégica de integração (Abetar, 2009). Em conformidade, Vasconcelos (2007), Silva et al. (2015) e Pignata et al. (2020) complementam que os aeroportos têm papel importante para o incremento de atividades econômicas, políticas e sociais, tanto em locais desenvolvidos quanto em desenvolvimento.

Deste modo, tendo em vista a sua localização estratégica na mesorregião do Baixo Amazonas o Aeroporto de Santarém e toda a sua infraestrutura, exerce papel fundamental por ser um agente integrador as regiões do país e um vetor para o desenvolvimento da localidade. Aliado a isso, surge à necessidade de o aeroporto dispor de infraestrutura adequada que garanta a segurança operacional exigida pela Agência Reguladora de Aviação Civil (Anac). Frisa-se que o tema infraestrutura é indispensável não somente para aviação, mas também em todos os ramos da sociedade, sobretudo, em áreas estratégicas como saúde, educação, acessibilidade, desenvolvimento social, industrial, comércio interno e externo, ou seja, impacta diretamente no resultado econômico da nação e por consequência no seu desenvolvimento (Miozzo, 2019).

Diante disso, a pesquisa tem como objetivo geral descrever a infraestrutura de sinalização luminosa vertical do Aeroporto de Santarém. Tendo como objetivos específicos mapear o que há instalado e comparar com as exigências normativas, sobretudo, os aspectos relacionados à quantidade de operações, layout do aeroporto e perspectivas de crescimento, relacionando tais itens com a segurança operacional.

\section{Aspectos Operacionais do Aeroporto de Santarém}

A grande extensão territorial do Brasil contribuiu diretamente na expansão do setor aéreo, principalmente devido à necessidade de percorrer grandes distâncias em menor tempo (Almeida, 2019). Segundo Lima et al. (2019) e Miozzo (2019) o aeroporto é essencial para o transporte aeroviário, haja vista ser o local onde ocorre a transferência dos modais de transportes, sobretudo, do aéreo para o terrestre ou vice-versa. Neste local há a integração dos principais componentes do setor aéreo que são: usuário, empresas aéreas e o aeroporto. Por isso a importância de prevê a infraestrutura mínima para processar as operações, ou seja, criar parâmetros básicos para definir a capacidade aeroportuária, capacidade de voos por hora pico e demanda de passageiro.

Diante dessa importância, a Anac surge como uma agência reguladora federal, a qual é responsável por normatizar e supervisionar a atividade de aviação civil no Brasil, tanto nos aspectos econômicos, quanto no que diz respeito à segurança técnica do setor. A Anac dispõe sobre as características físicas mínimas as quais devem dispor o aeródromo, de acordo com a operação a ser executada, ou seja, define a necessidade de implantação ou não de balizamento, sinalização vertical, cerca operacional, dimensões das pistas de taxiways, sinalização horizontal etc. 


\subsection{Planejamento do sistema de sinalização vertical}

Para Medau (2011) o aeroporto é um conjunto de elementos agrupados em áreas especificas, de forma sinergética para atender as demandas área e terrestre. O estudo em epígrafe terá como foco uma análise do lado aéreo, principalmente, no que tange à sinalização vertical luminosa.

A Instrução Suplementar da Anac IS153-109 descreve que para o planejamento de sinalização vertical deve-se pensar de maneira lógica e simples na designação das pistas de táxi, pistas e pátio principal. Além disso, deve-se analisar as principais características do aeroporto as quais são: padrão de movimentação de solo, a existência de torre de controle, localização dos terminais, número de operações e tipos de operadores. A IS 153-109 também descreve alguns princípios conforme a Figura 1:

Figura 1 - Princípios a serem seguidos no projeto de sinalização vertical.

\begin{tabular}{|l}
$\begin{array}{l}\text { • Sinalização vertical de instrução obrigatória de designação de pista, deve ser instalada com } \\
\text { uma informação de localização na posição de espera da pista de táxi com acesso a pista de } \\
\text { pouso e decolagem; }\end{array}$ \\
\hline $\begin{array}{l}\text {-Não instalar sinalizações verticais em trecho da pista de táxi entre a sinalização vertical de } \\
\text { instrução obrigatória de designação de pista e a cabeceira de pista de pouso e decolagem; }\end{array}$ \\
\hline $\begin{array}{l}\text { Q Quando for necessário proteger o sinal de um auxílio à navegação aérea ou determinado } \\
\text { espaço aéreo, instalar uma sinalização vertical de instrução obrigatoria em qualquer pista de } \\
\text { taxi no ponto limite para proteger a área crítica do auxilio ou a superficie de aproximação }\end{array}$ \\
\hline $\begin{array}{l}\text {-Instalar uma sinalização vertical de informação de direção antes de cada interseção entre } \\
\text { pistas de táxi quando for esperado que uma aeronave normalmente faça a curva ou tenha que } \\
\text { esperar na interseção. }\end{array}$ \\
\hline $\begin{array}{l}\text {-Em aeroportos não controlados, é preferivel que as sinalizações verticais de localização e } \\
\text { direção sejam usadas no lugar daquelas que informam destino. }\end{array}$ \\
\hline $\begin{array}{l}\text { - Instalar sinalizações de "Pare" de acordo com os manuais brasileiros de sinalização de } \\
\text { trânsito em cada via de serviço que intersecta uma pista de pouso e decolagem ou uma pista } \\
\text { de táxi; }\end{array}$ \\
\hline $\begin{array}{l}\text {-Instalar sinalizações verticais adicionais na área de movimento onde houver necessidade de } \\
\text { eliminar confusões ou prover confirmação de localização }\end{array}$ \\
\hline
\end{tabular}

Fonte: Adaptado Anac (2020).

No que tange a localização e características da sinalização vertical, de acordo com Anac Rbac nº154, as sinalizações verticais devem ser frangíveis, sendo que aquelas situadas próximas à pista de pouso e decolagem ou de táxi devem ser baixas o suficiente para manter a desobstrução das hélices e naceles dos motores de aeronaves a jato. A altura de instalação/localização da sinalização vertical não deve exceder as dimensões exibidas na Tabela 1. 
Tabela 1 - Altura da sinalização vertical.

\begin{tabular}{|c|c|c|c|c|c|}
\hline \multicolumn{4}{|c|}{ Altura da sinalização vertical (mm) } & \multirow{2}{*}{$\begin{array}{c}\text { Distância } \\
\text { perpendicular da } \\
\text { borda da pista de } \\
\text { táxi à lateral mais } \\
\text { próxima da } \\
\text { sinalização vertical }\end{array}$} & \multirow{2}{*}{$\begin{array}{c}\text { Distância perpendicular } \\
\text { da pista de pouso e } \\
\text { decolagem à lateral mais } \\
\text { próxima da sinalização } \\
\text { vertical }\end{array}$} \\
\hline $\begin{array}{l}\text { Número do } \\
\text { código }\end{array}$ & Legenda & Fase (min) & Instalada (max.) & & \\
\hline 1 ou 2 & 200 & 400 & 700 & $5-11 \mathrm{~m}$ & $3-10 m$ \\
\hline 1 ou 2 & 300 & 600 & 900 & $5-11 \mathrm{~m}$ & $3-10 \mathrm{~m}$ \\
\hline 3 ou 4 & 300 & 600 & 900 & $11-21 \mathrm{~m}$ & $8-15 m$ \\
\hline 3 ou 4 & 400 & 800 & 1100 & $11-21 \mathrm{~m}$ & $8-15 m$ \\
\hline
\end{tabular}

Fonte: Adaptado Rbac 154 (Anac, 2020).

Ainda de acordo com a Anac, as sinalizações verticais devem ser retangulares. Outro fator importante, é que as únicas sinalizações verticais na área de movimento a utilizar o vermelho deverão ser as sinalizações verticais com instruções obrigatórias. Já as sinalizações verticais de informação, devem atender os seguintes parâmetros: se a informação é de localização, as cores são inscrição amarela sobre um fundo preto; se a sinalização horizontal de informação é de direção, as cores são inscrição preta sobre um fundo amarelo.

Quanto à iluminação de sinalizações verticais, estas devem existir quando destinadas ao uso em condições de alcance visual de pista com valores inferiores a $800 \mathrm{~m}$; durante a noite, em associação a pistas de operação por instrumento; ou durante a noite, em associação com pistas de não instrumento onde o número de código for 3 ou 4. Para Santarém, por ser uma pista de pouso com código 4 e operação por instrumento e visual diurno e noturno, torna-se obrigatório o uso de iluminação, de acordo com o Rbac 154 (Anac, 2019).

Na alimentação das luzes dos Sistemas Vertical utilizam-se os seguintes componentes: reguladores de corrente constante, transformadores de isolamento, kit conector, cabos de média tensão, caixas de passagens e linhas de dutos. O circuito normalmente utilizado é o série constituído de cabos isolados de média tensão, de $3,6 / 6 \mathrm{kV}$, que se conectam às luminárias através de transformadores isoladores de potência apropriada. Destaca-se que a utilização do circuito série deve-se as vantagens deste tipo de conexão, principalmente por possibilitar que todas as lâmpadas trabalhem na mesma corrente e consequentemente na mesma intensidade; pode ser usado um condutor singelo de mesma bitola e classe de tensão de isolamento no circuito; o controle de intensidade das luzes pode ser obtido através de uma larga faixa; e faltas para terra são fáceis de serem localizadas.

Os transformadores de isolamento são utilizados comumente em circuitos séries de aeródromo para isolar eletricamente os dispositivos de iluminação, com isso em caso de falhas de lâmpadas o transformador garante a continuidade do circuito. Para sua instalação é necessário considerar que estejam fora dos limites do acostamento da pista, em caixas apropriadas, dotadas de dreno, e de suporte que evitem que eles fiquem em contato com o solo, haja vista a possibilidade de fugas para terra. Os transformadores devem estar de acordo com a Nbr 9718/2013 fabricados com baixas perdas e sua corrente primária e secundária de $6,6 \mathrm{~A}, 60 \mathrm{~Hz}, 5 \mathrm{kV}$. As conexões dos transformadores com o cabo de média tensão é feita por meio de conectores para cabo de $10 \mathrm{~mm}^{2}$, com isolamento para $5 \mathrm{kV}$.

Já os reguladores de corrente constante são instalados na casa de força onde recebem alimentação em corrente alternada de baixa tensão e gera corrente constante com derivações nas faixas de $2.8 \mathrm{~A}$ à $6,6 \mathrm{~A}$, independente da resistência do circuito utilizador, desta forma, é possível ajustar o brilho adequado da sinalização luminosa. Os reguladores são formados por um núcleo envolvente com colunas sobre o qual estão colocados os dois enrolamentos, primário e secundário, representados por duas bobinas. 
A subestação destinada a abrigar os equipamentos de comando, controle, supervisão e proteção dos sistemas de iluminação das placas de sinalização vertical, sempre que possível, deverá ser localizada o mais próximo do centro de cargas da instalação, e ter possibilidade de acesso fácil e rápido em qualquer circunstância, sem interferir com a operação do aeroporto.

Ademais, é importante que o sistema de energia do aeroporto seja dotado de uma fonte secundária, ou seja, fornecida por um grupo gerador de emergência, de funcionamento automático, que ficará preparado para partir e assumir carga imediatamente após uma falha do sistema normal. De acordo com o Rbac 154.501 (Anac, 2019), a segurança das operações em aeródromos depende da qualidade da energia elétrica suprida.

Vale destacar, que para aeródromos o intervalo de tempo entre a falha da fonte primária de energia e a restauração completa dos serviços deve ser tão curto quanto possível, exceto quando relativo a auxílios visuais associados a aproximação de não-precisão, aproximação de precisão ou pistas utilizadas para decolagem, caso em que deverão ser aplicados os requisitos do Rbac 154 (Anac, 2019). Para o aeroporto de Santarém o tempo máximo para comutação é de 15 segundos, ou seja, em caso de interrupção de energia por parte da concessionária o grupo gerador deve assumir a carga de auxílios visuais no máximo em 15 segundos.

É importante que a subestação disponha de malha de aterramento, adequadamente dimensionada para evitar potenciais de passo e toque que possa colocar em risco a vida de pessoas, quando de uma falha de isolamento de algum componente. Esta malha deverá estar conectada aos cabos de descida do Sistema de Proteção contra Descargas Atmosféricas (Spda), de forma a se evitar diferenças de potenciais passíveis de provocar danos a pessoas e/ou equipamentos sensíveis. Todas as partes metálicas da subestação deverão ser solidamente ligadas à malha, inclusive o sistema de aterramento dos equipamentos de pista. Esta conexão deverá ser realizada por meio de solda exotérmica e todas as partes metálicas móveis de painéis, armários ou equipamentos, tais como portas, gavetas etc., deverão ser acopladas à parte fixa por meio de cordoalhas flexíveis de cobre. Destaca-se que o sistema de aterramento da subestação deve seguir a ABNT NBR 15751/13.

No que se refere as placas de sinalização vertical o tipo de lâmpada a ser utilizada pode ser incandescente ou tecnologia à Led. A tecnologia O Led não é uma invenção recente, foi desenvolvida em fase experimental em 1963, tinha baixa luminosidade e cor vermelha. Em 1975, descobriu-se o de cor verde e em 1995 de cor branca. Atualmente, a tecnologia a Led vem sofrendo várias evoluções, porém, essas descobertas iniciais foram fundamentais para chegar ao resultado atual (Santos et., 2015).

\section{Metodologia}

A pesquisa tem como base em uma investigação de campo nas instalações do Aeroporto, na cidade de Santarém, que tem por natureza uma pesquisa aplicada. De acordo com Gerhardt e Silveira (2009, p.35) "este tipo de pesquisa tem como objetivo gerar conhecimentos para aplicação prática, dirigidos à solução de problemas específicos”. Para Ferrari (1982, p. 171), "não obstante a finalidade prática da pesquisa, ela pode contribuir teoricamente com novos fatos para o planejamento de novas pesquisas ou mesmo para a compreensão teórica de certos setores do conhecimento". Destarte os procedimentos metodológicos foram divididos em quatro etapas: caracterização do objeto de estudo; mapeamento das prescrições normativas; elaboração do projeto de sinalização vertical; análise dos resultados.

\subsection{Caracterização do objeto de estudo}

Em se tratando do Aeroporto de Santarém, após levantamentos realizados junto à Anac, Departamento de Controle do Espaço Aéreo (Decea) e visitas in loco organizou-se o Quadro 1 que mostra as informações do aeroporto, as quais serão utilizados na análise de resultados para evidenciar se há necessidade de implantação de um sistema de sinalização vertical. 
Quadro 1: Características do Aeroporto de Santarém.

\begin{tabular}{|l|l|}
\hline Pista de pouso e decolagem & Uma pista \\
\hline Dimensões da pista de pouso e decolagem & $2400 \mathrm{~m}$ x 45m \\
\hline Pátios de Aeronaves & Pátio principal (aviação regular) e Pátio Auxiliar (aviação geral) \\
\hline Cabeceiras & $\begin{array}{l}\text { Cabeceira 10 } \\
\text { Cabeceira 28 }\end{array}$ \\
\hline Aeronave crítica & 4 C \\
\hline Horário de funcionamento & H24 \\
\hline Serviços de Navegação Aérea & Torre de controle, controle de aproximação e estação meteorológica \\
\hline Tipos de tráfegos para passageiros & Doméstico regular e não regular; aviação geral \\
\hline Movimentação de passageiros 2019 & 514.000 \\
\hline Movimentação de aeronaves 2019 & 10.452 \\
\hline Horário pico & Inferior a 5 movimentos \\
\hline Taxiways & $\begin{array}{l}04 \text { taxiways denominada como Alfa (A), Bravo (B), Charlie (C) e } \\
\text { Delta (D) }\end{array}$ \\
\hline Auxilios Visuais & $\begin{array}{l}\text { Balizamento, Indicador de Trajetória de Aproximação de Precisão } \\
\text { (PAPI), Farol de Aeródromo e Indicador Visual de Condições do } \\
\text { vento de superfície (BIRUTA) }\end{array}$ \\
\hline Sinalização Vertical & Instalada, porém não atende aos padrões normativos. \\
\hline
\end{tabular}

Fonte: Adaptado de Anac, Decea e Infraero (2020).

Para compreender os dados do Quadro 1 faz-se necessário definir alguns conceitos:

- $\quad$ Pistas de pouso e decolagem: significa a área retangular, definida em um aeródromo em terra, preparada para pousos e decolagens de aeronaves. (Anac, Regulamento Brasileiro de Avaiação Civil - Rbac - no 154 - Emenda no 06, 2019, p.12).

- Hora-pico significa o intervalo de 60 (sessenta) minutos mais movimentados no dia médio do mês pico do ano civil (Anac, Rbac no 153 - Emenda n ${ }^{\circ}$ 05, 2019, p. 6).

- Densidade de tráfego do aeródromo significa o número médio de movimentos na hora-pico, sendo representada pela média aritmética de movimentos na hora-pico de cada dia ao longo de um ano, podendo ser classificada como (Anac, Rbac $\mathrm{n}^{\circ}$ 154 - Emenda no 06, 2019, p. 9):

- Baixa - quando o número médio de movimentos na hora-pico, por pista de pouso e decolagem, for igual ou inferior a 15; ou for inferior a 20, quando considerada a totalidade de movimentos do aeródromo;

- Média - quando o número médio de movimentos na hora-pico, por pista de pouso e decolagem, for superior a $15 \mathrm{e}$ inferior a 26; ou for igual ou superior a 20 e igual ou inferior a 35, quando considerada a totalidade de movimentos do aeródromo; - Alta - quando o número médio de movimentos na hora-pico, por pista de pouso e decolagem, for igual ou superior a 26; ou for superior a 35, quando considerada a totalidade de movimentos do aeródromo.

- $\quad$ Quanto ao layout do aeroporto, classifica-se (Anac, Instrução Suplementar IS 153.109):

- Configuração básica: aeródromo com uma pista de pouso e decolagem, com uma pista de táxi levando a um pátio de estacionamento de aeronaves;

- Configuração simples: aeródromo com uma pista de pouso e decolagem, com mais de uma pista de táxi levando a um ou mais pátios de estacionamento de aeronaves; e

- Configuração complexa: aeródromo com mais de uma pista de pouso e decolagem, com muitas pistas de táxi levando a um ou mais pátios de estacionamento de aeronaves. 
- Sinalização vertical significa a informação aeronáutica que compõe os auxílios visuais à navegação aérea composta por placas ou painéis destinados a fornecer mensagens (Anac, Rbac no 154 - Emenda $n^{\circ} 06,2019$, p. 14).

\subsection{Mapeamento das prescrições normativas}

Compreender as normas vigentes aplicadas a aeroportos é uma etapa fundamental, entretanto, frisa-se que a norma de aviação civil é ampla e abrange aeroportos com diversas operações, portanto, deve-se caracterizar o aeroporto e verificar que horizonte pretende alcançar. Caso contrário, o projeto de sinalização vertical pode em um curto intervalo de tempo ser obsoleto ou sobredimensioado, em ambas as situações poderão ocorrer um desperdício de dinheiro público.

Para o presente trabalho foi realizada uma pesquisa de dados no Rbac $n^{\circ} 154$ Emenda $n^{\circ} 06$, a qual versa sobre as regras a serem adotadas nos Projetos de Aeródromos, ou seja, na elaboração de projetos os aeródromos brasileiros devem seguir as diretrizes do documento. $\mathrm{O}$ Rbac n ${ }^{\circ} 153$ Emenda 05 que estabelece os parâmetros para Operação, Manutenção e Reposta à Emergência dos aeródromos brasileiros. Por fim, a Publicação de informação aeronáutica-Brasil (AIP-Brasil) que apresenta as informações e especificações técnicas dos aeroportos brasileiros.

Neste contexto, foi elaborado um check-list com os principais fatores que devem ser considerados na determinação da localização e do tipo de sinalizações verticais que devem ser instaladas (Figura 2).

Figura 2 - Check-list do projeto de sinalização vertical.

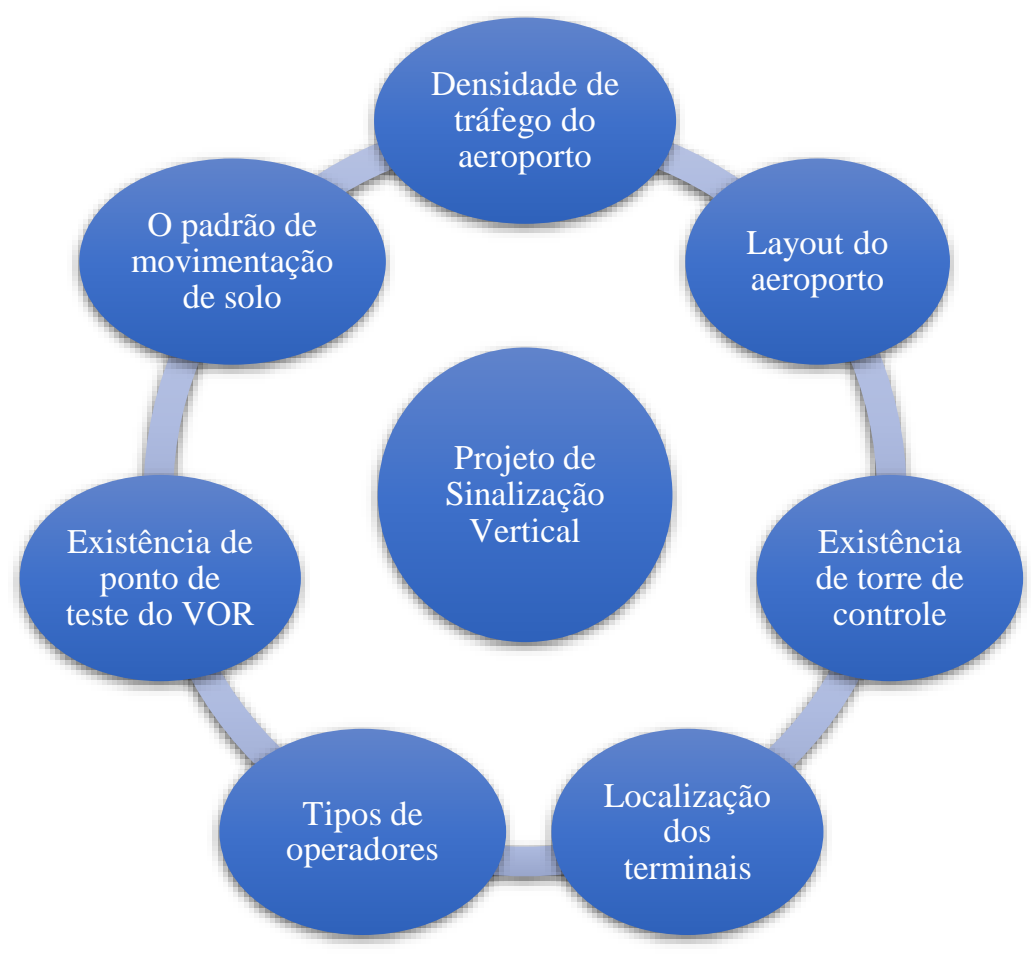

Fonte: Adaptado Anac (2020).

A Figura 2 pode ser utilizada como diretriz no processo de elaboração do projeto sinalização vertical para qualquer aeródromo, pois com base nos fatores elencados será possível definir a necessidade ou não de sua implantação, a localização das placas, bem como os tipos que devem ser instaladas. Desta forma, o presente do trabalho utilizou a sequência acima na definição do projeto. 


\subsection{Elaboração do projeto de sinalização vertical}

Para elaboração do projeto de sinalização vertical utilizou-se o AutoCad 2019 versão estudantil, sendo possível definir o layout das placas, suas locações, formas de ligação, cores e tipo de ligação elétrica.

\subsection{Análise técnica dos resultados}

De posse dos dados coletados in loco e pesquisa documental foi possível apresentar os resultados da caracterização do aeroporto, assim como sugerir um projeto para implantação de sinalização vertical, especificando de maneira sequencial o tipo de placa a ser utilizada, os transformadores, as conexões e abrigos metálicos.

Em síntese, a pesquisa concentrou-se em elaborar um diagnóstico e propor um procedimento metodológico a ser utilizado para elaboração de sistemas de sinalização vertical, ou seja, atender a uma demanda gerada por "clientes, atores sociais ou instituições" (Thiollent, 2009, p.36).

\section{Resultados e Discussão}

Com base na caracterização do aeroporto, normas vigentes e quantidades de operações é possível classificar o aeroporto e elaborar um projeto de sinalização vertical. Nesse sentido, à luz do Rbac nº 154 Emenda n ${ }^{\circ} 06$, o aeródromo será classificado como densidade de tráfego baixa e quanto ao layout configuração simples, tendo em vista, respectivamente, dispor de número de movimentos na hora pico inferior a 15 movimentos; e possuir somente uma pista de pouso e decolagem com mais de uma pista de táxi, levando a um ou mais pátios de estacionamento de aeronaves.

Outro ponto relevante, verificado in loco, são as características das atuais placas de sinalização vertical do aeroporto, pois apesar de existirem, não atendem aos padrões mínimos de tamanho, localização e quantidades exigidas. É importante ressaltar, que de acordo com a Instrução Suplementar da Anac IS 153-109, um sistema de sinalização vertical corretamente projetado e padronizado é fundamental para a segurança operacional e eficiência das operações das aeronaves e veículos na área de movimento, sendo que este deve prover de:

- $\quad$ Capacidade de informar facilmente a posição na qual a aeronave está localizada;

- $\quad$ Rápida identificação da rota a ser seguida para chegar ao destino desejado;

- Identificação das posições de espera; e

- Identificação dos limites para proteger superfícies limitadoras de obstáculos e áreas críticas dos auxílios a navegação aérea.

Ademais, reprisa-se que o fato de o aeroporto não dispor de sinalização vertical pode se tornar um empecilho, caso haja uma demanda de crescimento no número de operações, tendo em vista a segurança das operações. Além disso, em conversas com os gestores do aeroporto observou-se nenhuma exigência por parte da Anac para a implantação de sinalização vertical, entretanto, ressaltaram que de acordo com a Portaria No 908/SAI/2016 há uma restrição para aumentar as frequências de operações semanais, sendo a sinalização luminosa vertical um dos fatores, por isso a relevância de realização de um planejamento para a implantação do sistema.

Frisa-se que o planejamento do sistema aeroportuário define as instalações necessárias para atender as necessidades atuais e futuras de uma região, estado ou país (Oliveira Sobrinho, 2016). Nesta etapa apresenta-se também os benefícios da implantação do projeto de sinalização vertical, enfatizando os ganhos que esse projeto aliado a outros, poderá trazer para o Aeroporto de Santarém.

O projeto sugerido para o aeroporto consiste na definição dos tipos de placas, descrição de informaçães, transformadores, abrigo metálico e placa base para abrigo metálico, kit conectores. 


\subsection{Painéis de Sinalização Vertical Luminosa - Instrução Obrigatória}

Tendo em vista que o aeródromo possui duas taxiways que fazem interseção com a pista de pouso e decolagem, faz-se necessário a instalação de sinalização vertical luminosa de instrução obrigatória, conforme preconiza o Rbac 154.307 (b) (Anac, 2019). As Figuras 3 e 4 apresentam modelos de placas a serem instalados nas taxiways, respectivamente.

Figura 3 - Placa de instrução obrigatória taxiway alfa.

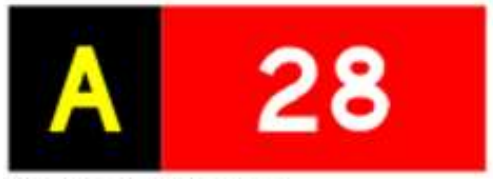

$800 \times 2300 \mathrm{~mm}$

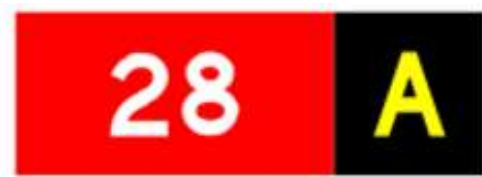

$800 \times 2300 \mathrm{~mm}$

Fonte: Adaptado Anac (2019).

Figura 4 - Placa de instrução obrigatória taxiway bravo.

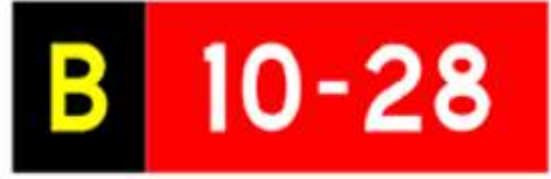

$800 \times 2700 \mathrm{~mm}$

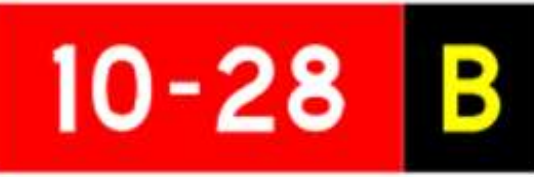

$800 \times 2700 \mathrm{~mm}$

Fonte: Adaptado Anac (2019).

\subsection{Painéis de Sinalização Vertical Luminosa - Ponto de Teste de VOR do Aeródromo.}

Observou-se in loco que as taxiways possuem sinalização horizontal de ponto de teste do sistema convencional de rádio - navegação para aeronaves (Vor). Neste contexto, como versa o item Rbac 154.307 (b) (Anac, 2019) torna-se necessário a instalação de placa vertical. Destaca-se que a sinalização vertical de ponto de Vor de aeródromo deve estar situada o mais próxima possível do ponto de teste, para isto, segue um modelo placa (Figura 5).

Figura 5 - Placa de ponto de teste do VOR.
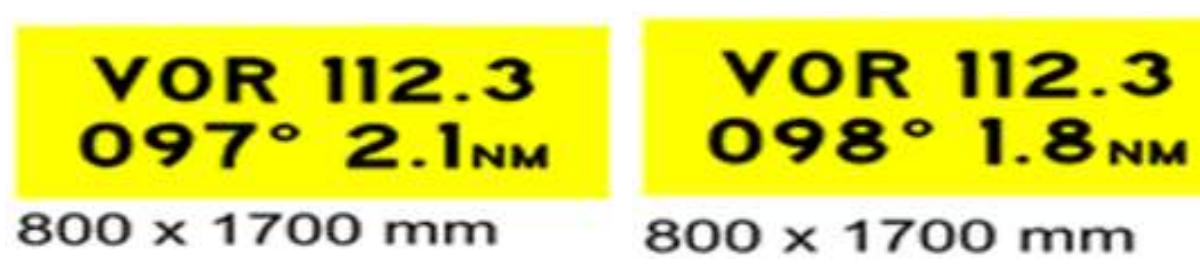

Fonte: Adaptado Anac (2019).

\subsection{Painéis de Sinalização Vertical Luminosa - Informação}

Ao seguir o mesmo arcabouço normativo do Rbac154 (Anac, 2019), torna-se necessário a instalação de placas de sinalização vertical luminosa de informação, visando atender uma necessidade operacional de identificação de uma saída de pista. Deste modo, como há possibilidade de uma aeronave realizar o pouso pelas duas cabeceiras, então é preciso que seja feita a locação das placas considerando que a aeronave poderá operar de ambos os lados, ou seja, pousando pela cabeceira 28 ou cabeceira 10. Com isso, as placas adequadas para o local estão descritas na Figura 6. 
Figura 6 - Placas de Sinalização Vertical de Informação.

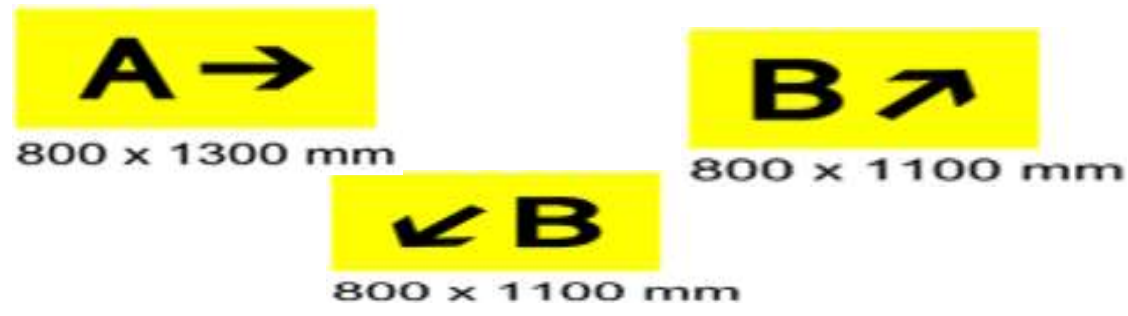

Fonte: Adaptado Anac (2019).

\subsection{Painéis de Sinalização Vertical Luminosa - Destino}

A sinalização vertical de destino tem o intuito de indicar a direção para um determinado destino no aeródromo, tal como a área de carga, aviação geral etc. (Anac, 2019). O aeródromo de Santarém como não tem área de carga, sugere-se a instalação de duas placas de sinalização vertical com destino ao pátio principal de aeronaves (Figura 7).

Figura 7 - Placas de Sinalização Vertical de Destino.

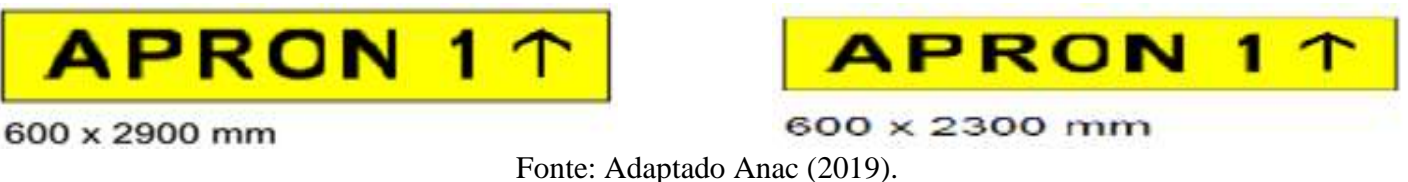

Fonte: Adaptado Anac (2019).

\subsection{Painéis de sinalização vertical luminosa de direção}

No que tange a sinalização vertical de direção (Figura 8), esta deve ser instalada para ressaltar uma localidade específica ou trajetória, que deve conter uma informação alfanumérica ou alfabética e uma seta (Anac, 2019). Para o trabalho em tela, recomenda-se a instalação de uma placa de direção no pátio principal, com isso será possível orientar o piloto a direção de cada cabeceira.

Figura 8 - Placas de sinalização vertical de direção.

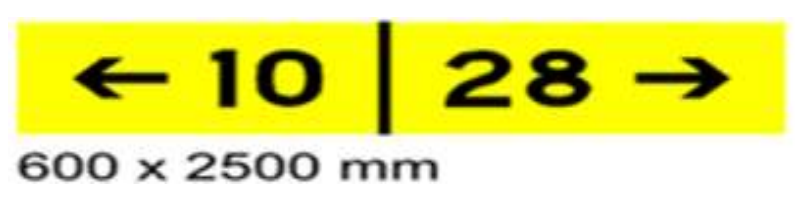

Fonte: Adaptado Anac (2019).

\subsection{Painéis de sinalização vertical luminosa - Localização/Direção}

O Rbac 154 prevê que uma sinalização vertical luminosa de localização/direção pode ser utilizada em conjunto (Anac, 2019). No aeroporto de Santarém serão instaladas placas de direção e localização sempre antes de cada interseção das pistas de táxis, em um local em que é esperado que uma aeronave normalmente faça a curva ou tenha que esperar na interseção. (Figura 9). 
Figura 9 - Placas de sinalização vertical de localização/Direção.

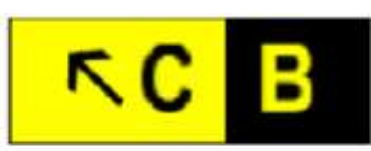

$600 \times 1500 \mathrm{~mm}$

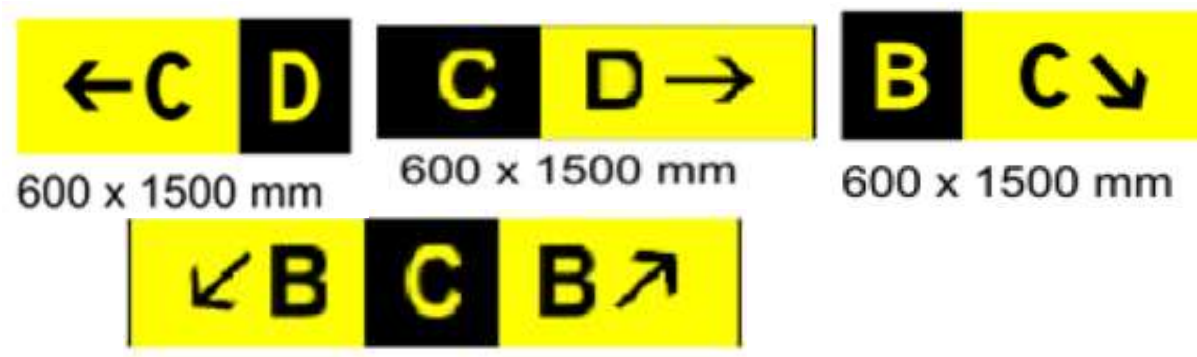

$600 \times 2300 \mathrm{~mm}$

Fonte: Adaptado Anac (2019).

\subsection{Transformador de isolamento para circuito série}

Para definição da potência de cada transformador de isolamento utilizou-se o folheto de especificações técnicas das empresas referências no mercado em fabricação de produtos para aeroportos. Assim como, considerou-se a tecnologia a Led.

Os transformadores de isolamento são comumente utilizados Com isso, serão necessários 14 transformadores de isolamento com potência de 300W e 03 transformadores de 500W. Sugere-se que o transformador deverá ter isolamento de 5KV; Eficiência > 70\%; Fator de Potência > 0,97; ser estruturado para instalação em caixa de passagem subterrânea; primário com corrente de até 6,6A/60Hz; conectores de entrada Classe A, com cabo de 0,6mm: Plug Estilo 2; receptáculo Estilo 9 e secundário: corrente de até $6,6 \mathrm{~A} / 60 \mathrm{~Hz}$.

\subsection{Placa de base para abrigo metálico - com acoplamento frangível e acessórios de instalação}

Segundo o Rbac 154 (Anac, 2019), nenhum objeto fixo excetuado os auxílios visuais necessários para fins de navegação aérea que satisfaçam os requisitos de frangibilidade, deve ser permitido em uma faixa de pista a uma distância de $60 \mathrm{~m}$ do eixo da pista.

Portanto, todas as placas de sinalização vertical devem ser frangíveis e sugere-se que no projeto conste: placa de base, com rosca fêmea de 2 polegadas parafusos de fixação da placa de base; grampo para receptáculo de Baixa Tensão de dois polos; abraçadeira e Parafusos do receptáculo; terminais de aterramento com parafusos e arruelas; junta de Vedação.

\section{Considerações Finais}

Com base no descrito, a pesquisa realizou o levantamento de dados do Aeroporto de Santarém e atingiu o seu objetivo de descrever como está configurada a estrutura de sinalização vertical, bem como sugerir um sistema moderno, eficiente e de acordo com as normas vigentes. Destaca-se que o presente trabalho serve como modelo para implantação de sistemas de sinalização vertical em aeroportos regionais que possuem as características de operações e layout semelhantes.

Ressalta-se os ganhos operacionais que a implantação do sistema pode gerar, pois a sinalização vertical é um dos itens requeridos no processo de certificação operacional, além disso, um aeroporto certificado poderá aumentar a quantidade de operações semanais permitidas. Há de se destacar os benefícios com a segurança operacional durante as operações, sobretudo, maior segurança aos pilotos durante o taxiamento da pista de pouso ao pátio de aeronaves.

Por fim, sugere-se a continuidade de estudos para trabalhos futuros sobre as demais condicionantes exigidas para a obtenção de certificação, relacionando-as aos impactos financeiros para a empresa administradora com o retorno operacional do aeroporto, assim como o ganho para a região no qual aeródromo está inserido, sobretudo, a prospecção de novos empreendimentos. Além de pesquisas sobre a implantação de energia fotovoltaica para alimentar o sistema de iluminação de 
placas de sinalização vertical, para verificar se a reflexões de luz das placas influenciariam na segurança da aviação civil, o ciclo de vida, aporte de recursos, economia de energia elétrica, operação e manutenção do projeto.

\section{Referências}

Abetar, Associação Brasileira das Empresas de Transporte Aéreo Regional (2009). Plano de competitividade. Transporte Aéreo Regional.

Abnt, Associação Brasileira de Normas Técnicas (2013). NBR 9718: Transformadores de isolamento para auxílios luminosos em aeroportos.

Abnt, Associação Brasileira de Normas Técnicas (2013). NBR 15751: Sistemas de Aterramento de subestações - Requisitos.

Almeida, M. C. (2019). Análise da gestão do aeroporto Brigadeiro Lysias Rodrigues em Palmas- TO com ênfase na conservação da fauna. Tese (Doutorado), Curso de Pós-Graduação em Ciências do Ambiente, Universidade Federal do Tocantins.

Anac, Agência Nacional de Aviação Civil (2016). Portaria nº908/SIA, de 13 de abril de 2016. Diário Oficial da União de 14 de abril de 2016 , Seção 1, p. 9.

Anac, Agência Nacional de Aviação Civil (2019). Regulamento Brasileiro da Aviação Civil RBAC, n 154: Projeto de Aeródromos. p. 1-253.

Anac, Agência Nacional de Aviação Civil (2019). Regulamento Brasileiro da Aviação Civil RBAC, n 153: Aeródromos - operação, manutenção e resposta à emergência. p. 1-114.

Anac, Agência Nacional de Aviação Civil (2020). Instrução Suplementar n 153-109 B: Sistema de orientação e controle da movimentação no solo. p. 1-97.

Decea, Departamento de Controle do Espaço Aéreo (2020). Informação aeronáutica-Brasil (AIP-Brasil). https://aisweb.decea.mil.br/?i=publicacoes\&p=aip.

Ferrari, A. L. (1982). Metodologia da pesquisa científica.: McGraw-Hill do Brasil.

Gerhardt, T. E., \& Silveira, D. T. (2009). Métodos de pesquisa. UFRGS.

Icao, International Civil Aviation Organization (2004). Aerodrome Design Manual: part 4 visual. p. 64.

Infraero, Empresa Brasileira de Infraestrutura Aeroportuária (2020). Histórico Aeroporto Internacional De Santarém. http://www4.infraero.gov.br/aeroportos/aeroporto-de-santarem-maestro-wilson-fonseca/sobre-o-aeroporto/historico/

Lima, C. L., Iamanaka, L. F., \& Okano, M. T. (2019). A proposta de valor de um Hub aeroportuário: uma análise sob a lente teórica dos modelos de negócios. Research, Society and Development, 9 (3), 1-18.

Medau, J. C. (2011). Análise de capacidade do lado aéreo de aeroportos baseada em simulação computacional: aplicação ao aeroporto de São Paulo Congonhas. Dissertação (Mestrado), Curso de Engenharia de Transportes, Escola Politécnica da Universidade de São Paulo.

Miozzo, L. G. (2019). Capacidade operacional e investimentos em infraestrutura no setor aeroportuário brasileiro do período de 2011-2016. Escola Nacional de Administração Pública. Brasília.

Oliveira Sobrinho, H. A. (2016). Análise da infraestrutura do lado aéreo do aeroporto internacional de navegantes. Trabalho de Conclusão de Curso (Graduação), Graduação em Engenharia Civil, Centro Tecnológico, Universidade Federal de Santa Catarina.

Pignata, G. S., Santos, F. B. C., \& Dantas, A. A. N. (2020). Aeroporto Internacional de Brasília Juscelino Kubitschek: antes e depois da Copa do Mundo2014. Research, Society and Development, 9 (10), 1-23.

Santos, T. S., Batista, M. C., Pozza, S. A., \& Rossi, L. S. (2015). Análise da eficiência energética, ambiental e econômica entre lâmpadas de led e convencionais. Engenharia Sanitária e Ambiental, 20 (4), 595-602.

Silva, E. A. M., Araujo Sobrinho, F. L., \& Fortes, J. A. A. S (2015). A importância geoestratégica do Aeroporto Internacional de Brasília no desenvolvimento do turismo regional. Caderno Virtual de Turismo, 15 (3), 305-307.

Silva, G. V., \& Guimaraes, J. L. C. (2019). A importância do turismo para o desenvolvimento econômico local: um estudo em Alter do Chão (Caribe Amazônico), Santarém, Pará, Brasil. TURyDES - Revista de Investigación en Turismo y desarrollo local, 12 (27), 01 - 16.

Thiollent, M. (2009). Metodologia de Pesquisa-ação: Saraiva.

Vasconcelos, L. F. S. (2007). O aeroporto como integrante de um projeto de desenvolvimento regional: a experiência brasileira. Dissertação (Mestrado), Departamento de Engenharia Civil e Ambiental, Universidade de Brasília. Brasília, DF. 